\title{
Mood changes associated with "end-of-dose deterioration" in Parkinson's disease: a controlled study
}

\author{
R CANTEllo, M Gilli, A RicCiO, B BERGAMASCO* \\ From 1st and 3rd* Department of Neurology, University School of Medicine, Turin, Italy
}

SUMMARY Fluctuations of mood and psychic activation were assessed in relation to "mobile" and "immobile" periods in 18 patients with Parkinson's disease presenting typical "end-of-dose deterioration". Twelve subjects with chronic but active rheumatoid arthritis presenting increased physical disability due to severe morning joint stiffness with a repetitive pattern of mobile and immobile periods acted as controls. The overall degree of disability and its fluctuations were close enough in the two groups for fair comparison of changes in affective behaviour. Temporary immobility was accompanied by adverse changes of mood and activation, which were significantly more marked in the Parkinson's disease group than in the controls, though to a lesser extent in those Parkinson's disease patients rated depressed even in their mobile periods. The possible correlation between mood changes and fluctuations of central dopaminergic function in the Parkinson's disease patients is discussed.

Together with its clinical relevance to disability, ${ }^{1-3}$ one of the most interesting aspects of depression in Parkinson's disease is the problem of its pathogenetic and pathophysiological mechanisms. There is no definite evidence for a "reactive" or for a "primary" genesis of Parkinson's disease depression. Obviously it could be conceived as a psychological reaction to long-lasting motor impairment and yet it often precedes the onset of motor impairment, ${ }^{3}$ and depression is reportedly more common among Parkinsonians than among patients with other, equally severe, chronic diseases. ${ }^{4}$ This being so, some authors have been tempted to attribute Parkinson's disease depression to the pathobiology of the disease itself. ${ }^{4-7}$ Some have attributed a pathophysiological role in Parkinson's disease mood disturbances to impairment of the mesocortical and mesolimbic dopaminergic pathways. ${ }^{56}$ These structures, which degenerate in many Parkinson's disease patients, ${ }^{89}$ have been shown to play a crucial role in the psychophysiological reinforcement/reward processes $^{6}$ which, in turn, are likely to be involved in the pathophysiology of "primary" or "endogenous" or "endo-

Address for reprint requests: Roberto Cantello MD, Clinica Neurologica dell'Università, Via Cherasco 15, 10126 Torino, Italy.

Received 21 May 1985 and in revised form 9 December 1985. Accepted 15 December 1985 genomorphic" 10 depression. Hence the suggested correlation between Parkinson's disease depression and impaired function of the mesocortical and mesolimbic dopamine systems. ${ }^{56}$ However, this fascinating hypothesis raises two more basic questions: can we adduce further data to prove the reactive or primary nature of Parkinson's disease depression? And can we establish any correlation between mood disturbances and central dopaminergic activity in Parkinson's disease? The on-off phenomenon in Parkinson's disease may provide relevant information. During motor swings the striatal dopaminergic function fluctuates "from one extreme to the other" 11 and it has been assumed that such changes occur in the other dopamine systems as well. ${ }^{11}{ }^{12}$ Fluctuations may perhaps occur in non-motor aspects of Parkinson's disease, if these aspects are dependent upon the functional integrity of dopamine systems. ${ }^{11} 12$ On this assumption, the on-off paradigm was used to investigate the possible relationship of cognitive function $^{1113}$ and nociception ${ }^{12}$ to central dopaminergic activity in Parkinson's disease. Brown et al ${ }^{11}$ have also focused on the "affect-arousal state" of swinging Parkinsonians, and found the "off" period to be accompanied by a definite worsening of this index. The association between on-off motor changes and mood swings was then strikingly pointed out by Hardie et al. ${ }^{14}$ 
Table 1 Some characteristics of the patient and the control group

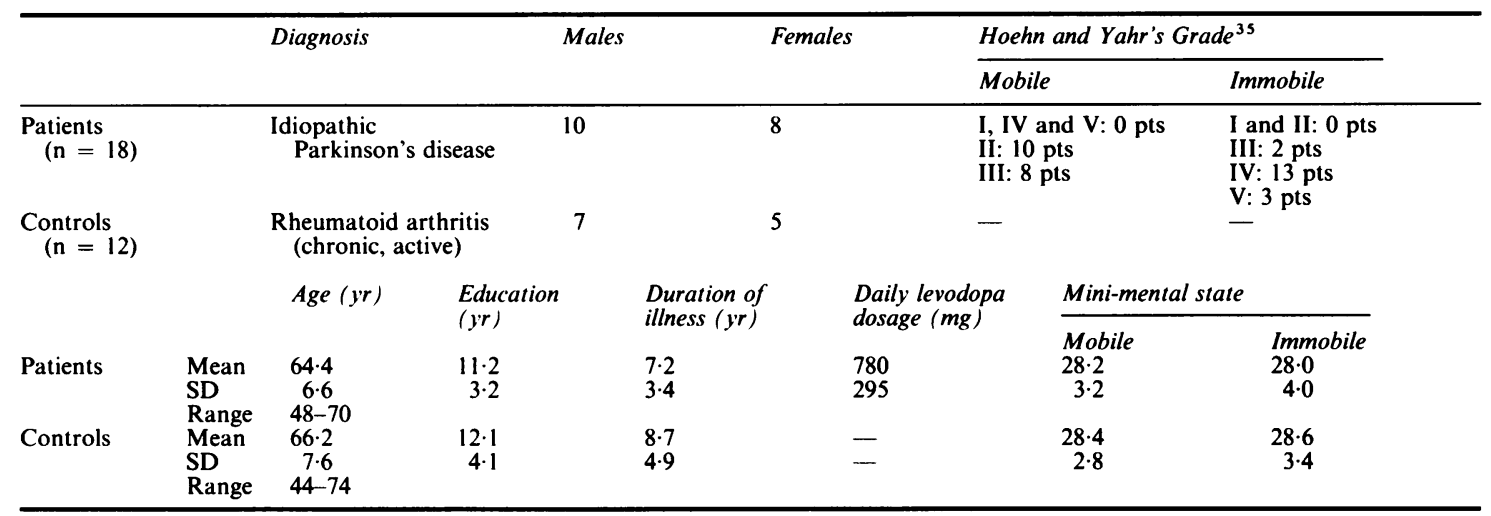

In the present study, affective behaviour was systematically investigated in a group of Parkinson's disease subjects during motor fluctuations. We attempted to identify mood swings and to define both their nature (reactive or primary) and their relationship to central dopaminergic function. For this purpose we used a controlled experimental situation, in which the affective behaviour of swinging Parkinson's disease patients was compared with that of a group of controls with similarly fluctuating motor disability, unrelated to CNS alterations.

\section{Patients and method}

Patients Consenting patients with idiopathic Parkinson's disease were selected for the study from those periodically examined at the Parkinson's disease Centre of the University Department of Neurology. Great care was taken to exclude subjects with Parkinsonism due to atherosclerosis or other causes. To this end, the subjects were admitted to the Neurological Department, where their complete case histories were recorded and where they underwent physical and neurological examination, EEG and CT brain scanning. Patients scoring above 4 on the Hachinski Ischemic Score ${ }^{15}$ and/or below 24 on the Mini-mental state ${ }^{16}$ (during both the "immobile" and the "mobile" period) were also excluded, as were patients with sudden capricious fluctuations in motor function ("yo-yo-ing"). ${ }^{17}$ The 18 patients finally selected (table 1) showed "end-of-dose deterioration" (EDD), ${ }^{17}$ a situation in which temporary brain dopaminergic deficiency seems to be unquestionable. ${ }^{17-19}$ All 18 patients had been taking levodopa (associated with carbidopa or benserazide) since the beginning of their illness. Their motor fluctuations were marked, but "immobile" periods never occurred abruptly, and the adverse influence on daily activities was often counterbalanced to some extent by adaptability.

Controls In partial accordance with the criteria indicated by Robins, ${ }^{4}$ we selected consenting nursing home patients suffering from chronic but active rheumatoid arthritis, as being as nearly as possible comparable to swinging Parkinson's disease patients. Twelve subjects carefully matched for age, sex, years of schooling and duration of illness acted as controls (table 1). As is typical of the disease, ${ }^{20}$ all of them showed marked fluctuations in physical disability, owing to severe reversible morning articular stiffness, associated with temporary pain exacerbation. Fluctuations in disability were fairly predictable and resembled those of Parkinson's disease patients in overall severity. No control had a family or personal history of previous "endogenous" depression. Neurological examination, EEG and CT brain scanning showed no focal signs of organic brain damage. During both their "mobile" and "immobile" periods the score on the Minimental state ${ }^{16}$ was above 24 in all subjects. Two controls had been taking psychotropic drugs, but these were stopped a month prior to examination. Anti-inflammatories were the only drugs allowed.

Assessment of disability and of affective behaviour Both Parkinson's disease patients and controls were rated on the scales described below by the same examiner (RC) on two occasions: once during a period of "mobility" (defined as the period in which the patients achieved their lowest score on the disability rating), and once during a period of "immobility" (the highest degree of disability resulting from EDD or from articular stiffness). This two-phase assessment was repeated 1 week later, with its sequence (mobile/immobile or immobile/mobile) reversed for both groups. Each subject was then assessed four times (twice mobile and twice immobile). The mean values were calculated for each phase. Care was taken to ensure that all the subjects were tested in identical enviromental conditions. All the controls were examined at $7 \mathrm{am}$ (immobile period) and at $11 \mathrm{am}$ (mobile period), which corresponded to the repetitive pattern of their articular stiffness. After a prolonged clinical observation, which enabled us to define the time pattern of their motor fluctuations, 12 out of the 18 Parkinson's disease patients were examined once at 9.30 am (mobile period) and again at 12 noon (immobile period preceding the next levodopa dose). In the remaining six Parkinson's disease subjects the motor pattern was less regular.

Disability The test used was the North Western University Disability Scale (NUDS), ${ }^{21}$ which rates hygiene, eating, dressing, gait and speech on a 0-10 scale. The maximum score was 50 points. 
Affective behaviour To obtain a reliable assessment of the behavioural manifestations of depression we used an Italian translation of the Beck Depression Inventory (BDI). ${ }^{22}$ BDI has often been used to study mood in Parkinson's disease patients ${ }^{122324}$ and it was considered to provide a good index at least for comparative purposes. ${ }^{24}$ As previously done, ${ }^{2}$ we gave a zero rating to items " $N$ " (body image), " $O$ " (work inhibition), "Q" (fatiguability) and " $T$ " (somatic preoccupation), as they would presumably be influenced by the increase in physical disability typical of the immobile period rather than by real mood changes. Since the assessment was repeated over very short intervals of time, a zero rating was given to item " $S$ " (loss of weight). This shortened version of the BDI (sBDI) carried a maximum score of 47 points. In addition, Parkinson's disease patients and controls were given an Italian translation of a shortened version of the Mood and Behaviour Self-Rating Scale, ${ }^{25}$ which included items ranging over a $0-6$ point scale of psychic activation and euphoria-related emotional states. This scale is often used for scoring the psychostimulant and euphoriant effects of amphetamines and methylphenidate, ${ }^{25}$ which are at least in part mediated via the mesocortical and mesolimbic dopamine pathways. ${ }^{26}$ In our view this Activation and Euphoria Scale (AES) (Appendix) provides not only a very simple and basic self-assessment of psychic activation, but also a more thorough evaluation of the affective state than the sBDI alone. The maximum score was 36 points.

DSM III criteria In order to obtain a more comprehensive psychiatric profile of Parkinson's disease patients and controls, depressive behaviour was also evaluated and classified (in the mobile period) according to the diagnostic criteria contained in the DSM III (Third Edition of the Diagnostic and Statistical Manual of the Mental Disorders of the American Psychiatric Association). ${ }^{27}$

Mini-mental State Cognitive performance was monitored in both groups during the "mobile" and the "immobile" period by means of the Mini-mental State. ${ }^{15}$ The maximum score was 30 points.

Statistics A high score on the NUDS, sBDI and AES denoted more severe disability, more severely depressed mood and increased activation and euphoria respectively. These data were analysed by means of the two-tailed Wilcoxon Signed Rank test, which was used to determine levels of significance of the mean differences, calculated within groups, between immobile and mobile values for each scale. Moreover, mean immobile and mobile values and mean (immobile-mobile) differences for each scale were compared in the two groups by means of the two-tailed Wilcoxon Rank Sum test. Within-group correlations were made by means of the two-tailed Spearman Rank correlation test.

\section{Results}

The numerical values are given in tables 2 and 3 .

As far as the test-retest reliability of the measures adopted is concerned, the correlations (Spearman Rank correlation test) between the scores obtained in the two immobile periods were the following: NUDS $=0.84$ (controls) and 0.89 (Parkinson's disease patients); sBDI $=\mathbf{0 . 8 1}$ (controls) and $\mathbf{0 . 8 3}$ (Parkinson's disease patients); AES $=0.86$ (controls) and 0.84 (Parkinson's disease patients). Between the two mobile assessments the correlations were: NUDS $=0.87$ (controls) and 0.88 (Parkinson's disease patients); sBDI $=0.80$ (controls) and 0.81 (Parkinson's disease patients); AES $=0.84$ (controls) and 0.84 (Parkinson's disease patients).

Disability The disability assessment of Parkinson's disease patients and controls is represented in fig 1. Obviously, the NUDS items were differently affected

Table 2 Assessment of disability, affective behaviour and psychic activation in Parkinson's disease patients during the mobile $(m)$ and the immobile (i) period

\begin{tabular}{|c|c|c|c|c|c|c|c|c|c|}
\hline \multirow[t]{2}{*}{ Patients } & \multicolumn{3}{|c|}{$N U D S$} & \multicolumn{3}{|l|}{$s B D I$} & \multicolumn{3}{|l|}{$A E S$} \\
\hline & $m_{m}$ & $i_{m}$ & $i_{m}-m_{m}$ & $m_{m}$ & $i_{m}$ & $i_{m}-m_{m}$ & $m_{m}$ & $i_{m}$ & $i_{m}-m_{m}$ \\
\hline $\begin{array}{l}1 \\
2 \\
3 \\
4 \\
5 \\
6 \\
7 \\
8 \\
9 \\
10 \\
11 \\
12 \\
13 \\
14 \\
15 \\
16 \\
17 \\
18 \\
\text { Mean } \\
\text { SD }\end{array}$ & $\begin{array}{l}10 \\
18 \cdot 5 \\
11 \cdot 5 \\
9 \cdot 5 \\
8 \cdot 5 \\
17 \cdot 5 \\
14 \\
10 \\
12 \cdot 5 \\
13 \\
8 \\
15 \cdot 5 \\
19 \\
13 \\
10 \cdot 5 \\
12 \\
16 \\
16 \\
13.05 \\
3.4\end{array}$ & $\begin{array}{l}26 \cdot 5 \\
34 \cdot 5 \\
33 \\
22 \cdot 5 \\
26 \cdot 5 \\
36 \\
30 \cdot 5 \\
24 \\
34 \\
30 \cdot 5 \\
34 \cdot 5 \\
34 \cdot 5 \\
42 \cdot 5 \\
29 \\
30 \\
30 \cdot 5 \\
34 \cdot 5 \\
36 \\
31 \cdot 63 \\
4 \cdot 87\end{array}$ & $\begin{array}{l}+16 \cdot 5 \\
+16 \\
+21 \cdot 5 \\
+13 \\
+18 \\
+18 \cdot 5 \\
+16 \cdot 5 \\
+14 \\
+21 \cdot 5 \\
+17 \cdot 5 \\
+26 \cdot 5 \\
+19 \\
+23 \cdot 5 \\
+16 \\
+19.5 \\
+18 \cdot 5 \\
+18.5 \\
+20 \\
+18.58 \\
3.27\end{array}$ & $\begin{array}{l}8 \\
22 \\
9 \cdot 5 \\
9 \\
19 \cdot 5 \\
15 \cdot 5 \\
7 \\
6 \\
8 \cdot 5 \\
14 \\
5 \cdot 5 \\
23 \cdot 5 \\
19 \\
8 \\
4 \cdot 5 \\
2 \cdot 5 \\
9 \\
32 \cdot 5 \\
12 \cdot 41 \\
8\end{array}$ & $\begin{array}{c}10 \cdot 5 \\
22 \cdot 5 \\
9 \cdot 5 \\
12 \\
19 \cdot 5 \\
16 \\
9 \cdot 5 \\
8 \cdot 5 \\
14 \\
15 \cdot 5 \\
6 \cdot 5 \\
24 \\
19 \cdot 5 \\
10 \cdot 5 \\
5 \\
4 \cdot 5 \\
13 \cdot 5 \\
34 \cdot 5 \\
14 \cdot 19 \\
7 \cdot 61\end{array}$ & $\begin{array}{c}+2.5 \\
+0.5 \\
0 \\
+3 \\
0 \\
+0.5 \\
+2.5 \\
+2.5 \\
+5.5 \\
+1.5 \\
+1 \\
+0.5 \\
+0.5 \\
+2.5 \\
+0.5 \\
+2 \\
+4.5 \\
+2 \\
+1.77 \\
1.53\end{array}$ & $\begin{array}{l}14 \cdot 5 \\
6 \\
10 \\
13 \\
6 \\
5 \cdot 5 \\
13 \cdot 5 \\
14 \\
10 \cdot 5 \\
8 \cdot 5 \\
14 \\
6 \\
7 \cdot 5 \\
12 \cdot 5 \\
12 \\
15 \\
11 \\
6 \\
10 \cdot 3 \\
3 \cdot 43\end{array}$ & $\begin{array}{l}6 \cdot 5 \\
5 \\
7 \cdot 5 \\
6 \cdot 5 \\
\cdot 5 \cdot 5 \\
4 \cdot 5 \\
7 \cdot 5 \\
8 \\
7 \cdot 5 \\
6 \\
8 \cdot 5 \\
4 \cdot 5 \\
6 \cdot 5 \\
9 \\
8 \cdot 5 \\
9 \cdot 5 \\
7 \\
4 \\
6 \cdot 77 \\
1 \cdot 62\end{array}$ & $\begin{array}{l}-8 \\
-1 \\
-2.5 \\
-6.5 \\
-0.5 \\
-1 \\
-6 \\
-6 \\
-3 \\
-2.5 \\
-5.5 \\
-1.5 \\
-1 \\
-3.5 \\
-3.5 \\
-5.5 \\
-4 \\
-2 \\
-3.52 \\
2.25\end{array}$ \\
\hline
\end{tabular}

Numerical values. NUDS $=$ North Western University Disability Scale. sBDI $=$ shortened Beck Depression Inventory. AES $=$ Activation and Euphoria Scale. $m_{m}=$ mean individual value of the two assessments in the mobile period. $\mathrm{i}_{\mathrm{m}}=$ mean individual value of the two assessments in the immobile period. 
Table 3 Assessment of disability, affective behaviour and psychic activation in controls during the mobile ( $m$ ) and the immobile (i) period. Numerical values. (For abbreviations see table 2)

\begin{tabular}{|c|c|c|c|c|c|c|c|c|c|}
\hline \multirow[t]{2}{*}{ Patients } & \multicolumn{3}{|c|}{ NUDS } & \multicolumn{3}{|l|}{$s B D I$} & \multicolumn{3}{|l|}{$A E S$} \\
\hline & $m_{m}$ & $i_{m}$ & $i_{m}-m_{m}$ & $m_{m}$ & $i_{m}$ & $i_{m}-m_{m}$ & $m_{m}$ & $i_{m}$ & $i_{m}-m_{m}$ \\
\hline 1 & $16 \cdot 5$ & $41 \cdot 5$ & +25 & $8 \cdot 5$ & 9 & +0.5 & 8 & $7 \cdot 5$ & -0.5 \\
\hline 2 & 9 & 38 & +29 & $14 \cdot 5$ & 15 & +0.5 & $10 \cdot 5$ & 10 & -0.5 \\
\hline 3 & $10 \cdot 5$ & 40 & +29.5 & 5 & 6 & +1 & 18 & 17 & -1 \\
\hline 4 & 18 & $22 \cdot 5$ & $+4 \cdot 5$ & 2 & $2 \cdot 5$ & +0.5 & 19 & 18 & -1 \\
\hline 5 & $13 \cdot 5$ & $26 \cdot 5$ & +13 & 1 & 2 & +1 & 20 & 19 & -1 \\
\hline 6 & 14 & $29 \cdot 5$ & +15.5 & 4 & 4 & 0 & $4 \cdot 5$ & $3 \cdot 5$ & -1 \\
\hline 7 & $8 \cdot 5$ & 27 & +18.5 & $2 \cdot 5$ & $2 \cdot 5$ & 0 & 18 & 18 & 0 \\
\hline 8 & 12 & $34 \cdot 5$ & $+22 \cdot 5$ & $12 \cdot 5$ & $13 \cdot 5$ & +1 & 10 & 9 & -1 \\
\hline 9 & 13 & 36 & +23 & $17 \cdot 5$ & 18 & +0.5 & 9 & $8 \cdot 5$ & -0.5 \\
\hline 10 & $7 \cdot 5$ & 29 & $+21 \cdot 5$ & 6 & 6 & 0 & 4.5 & $3 \cdot 5$ & -1 \\
\hline 11 & 8 & 38 & +30 & 7 & 8 & +1 & 6.5 & 6 & -0.5 \\
\hline 12 & $14 \cdot 5$ & $33 \cdot 5$ & +19 & 8 & 8 & 0 & 14 & $12 \cdot 5$ & $-1 \cdot 5$ \\
\hline Mean & $12 \cdot 08$ & 33 & +20.91 & $7 \cdot 37$ & $7 \cdot 87$ & +0.5 & 11.83 & 11.04 & -0.79 \\
\hline $\mathrm{SD}$ & 3.43 & 6.02 & $7 \cdot 48$ & $5 \cdot 16$ & $5 \cdot 22$ & 0.42 & $5 \cdot 74$ & $5 \cdot 73$ & 0.39 \\
\hline
\end{tabular}

by the different kind of motor impairment seen in the Parkinson's disease and the control subjects. However, when the mean NUDS scores achieved in the mobile period by Parkinson's disease patients and controls are compared, no significant difference appears. Moreover, both Parkinson's disease patients and controls show a highly significant $(p<0.01)$ mean increase in their overall disability (NUDS) scores during the immobile period. Finally, this increase in physical disability did not differ significantly between the two groups.

Affective behaviour Mean sBDI scores and their changes in Parkinson's disease subjects and in controls are shown in fig 2 . The values are very scattered, owing to the presence of individuals with high or very

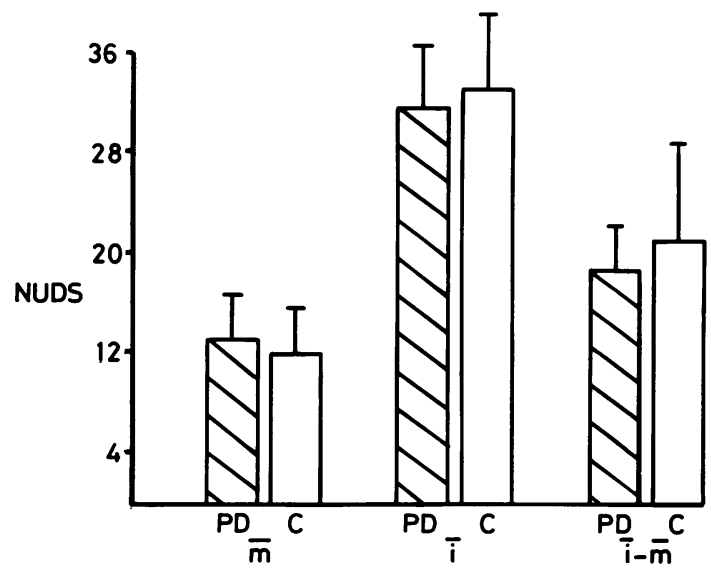

Fig 1 Mean mobile $(\bar{m})$ and immobile $(\bar{i})$ scores on the North Western University Disability Scale (NUDS) ${ }^{21}$ in the Parkinson (PD) and the Control (C) group. The difference $(\bar{i}-\bar{m})$ represents the mean increase in disability in the immobile period, which is quite similar in both groups. Bars represent $S D$. high depression scores. However, the two-tailed Wilcoxon Rank Sum test showed the mean mobile scores in the Parkinson's disease group to be significantly higher than that of controls $(p<0.05)$. During the immobile period there was an increase in the mean sBDI score of both Parkinson's disease patients and controls. This increase, albeit slight, is significant within the Parkinson's disease group $(p<0.05)$, while the opposite is true for controls. Moreover, the absolute (immobile-mobile) mean value is significantly higher in Parkinson's disease subjects than in controls $(\mathrm{p}<0.01)$.

When individual subjects were observed during the

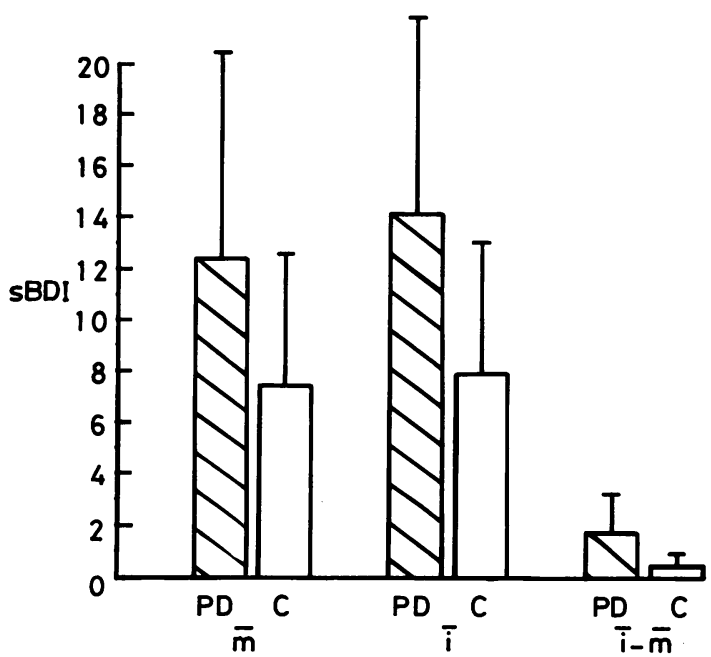

Fig 2 Mean mobile $(\bar{m})$ and immobile $(\bar{i})$ scores on the shortened Beck Depression Inventory (sBDI, see Methods) in the Parkinson (PD) and the Control (C) group. The difference $(\bar{i}-\bar{m})$ represents the mean increase in the $S B D I$ score during the immobile period, which is significantly higher in the $P D$ group $(p<0.01)$. Bars represent $S D$. 


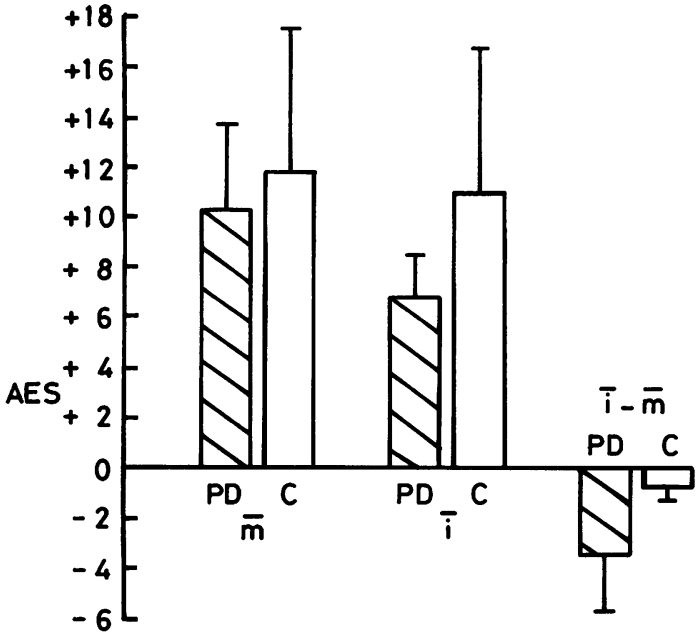

Fig 3 Mean mobile $(\bar{m})$ and immobile $(\bar{i})$ scores on the Activation and Euphoria Scale (AES) (Appendix) in the Parkinson (PD) and the Control (C) group. The difference $(\bar{i}-\bar{m})$ represents the mean decrease in the AES score during the immobile period, which is significantly greater in the $P D$ group $(p<0.001)$. Bars represent $S D$.

mobile period (tables 2 and 3), 7/18 (38.8\%) of Parkinson's disease patients and 3/12 $(25 \%)$ of controls scored above 10 points on the sBDI. According to Schwab et al, ${ }^{28}$ this fits the diagnosis of depression. Moreover, the seven Parkinson's disease patients scoring highly on the sBDI met the DSM III criteria ${ }^{27}$ for a "major depression". They had reportedly been showing signs and symptoms of depression for several years (mean $\pm S D=7.9 \pm 4 \cdot 1$ ); in three of them the onset of depression was described as nearly coinciding with the onset of Parkinson's disease motor disturbances, while in the remaining four depression had antedated the cardinal features of Parkinson's dis-

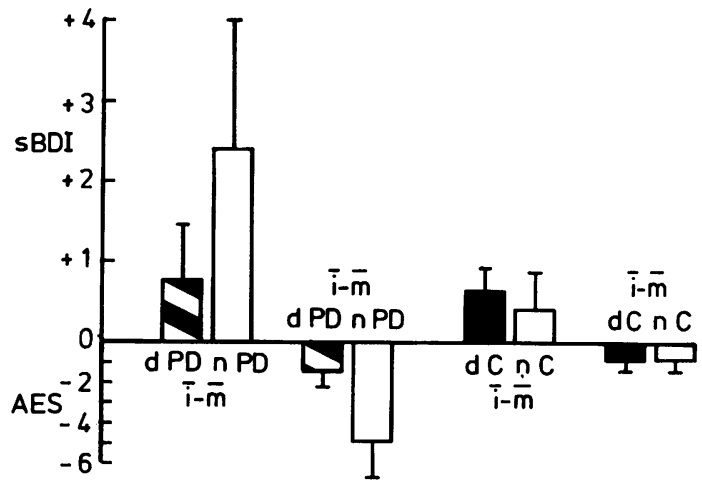

Fig 4 Comparison, within-groups, between "steadily depressed" and "non-steadily depressed" subjects and their changes of the SBDI and AES scores during the immobile period ( $\bar{i}-\bar{m}$ values). "Steadily depressed" $P D$ patients (dPD) show an increase in their SBDI and a decrease in their AES scores significantly lower than those of "non-steadily depressed" $P D$ patients ( $n P D)(p<0.05 ; p<0.01)$. This phenomenon is not observed among "steadily depressed" and "non-steadily depressed" Controls ( $d C$ and $n C$ respectively). Bars represent $S D$.

ease. On this basis, we rated these seven patients as "steadily depressed" Parkinsonians (dPD). They differed in affective behaviour during the immobile period from the remaining "non-steadily depressed" Parkinson's disease patients (nPD). Figure 4 shows that the (immobile-mobile) mean value on the sBDI in APD is significantly lower than the corresponding value in nPD ( $<<0.05$, Wilcoxon Rank Sum test). This difference was not observed between steadily depressed and non-steadily depressed controls, similarly defined (fig 4). (It must be emphasised that the three controls scoring highly on the sBDI in their mobile period met the DSM III diagnostic criteria ${ }^{27}$ for a "dysthymic disorder").

Table 4 Parkinson's disease patients. Spearman rank correlation coefficients for the main variables

\begin{tabular}{|c|c|c|c|c|c|c|}
\hline & $\begin{array}{l}\text { Duration of } \\
\text { illness }\end{array}$ & $\begin{array}{l}\text { Levodopa } \\
\text { dosage }\end{array}$ & $N U D S$ & $s B D I$ & $A E S$ & $\begin{array}{l}\text { Mini-mental } \\
\text { state }\end{array}$ \\
\hline $\begin{array}{l}\text { Age } \\
\text { Duration of illness } \\
\text { Levodopa dosage } \\
\text { NUDS } \\
\text { sBDI } \\
\text { AES }\end{array}$ & 0.26 & $\begin{array}{l}0.14 \\
0.52^{*}\end{array}$ & $\begin{array}{c}\text { ile values } \\
0.36 \\
0.56^{*} \\
0.50^{*}\end{array}$ & $\begin{array}{c}-0.08 \\
0.26 \\
0.13 \\
0.54^{*}\end{array}$ & $\begin{array}{c}0.11 \\
-0.34 \\
0.11 \\
-0.57 * \\
-0.89 \dagger\end{array}$ & $\begin{array}{r}-0.40 \\
-0.38 \\
-0.21 \\
-0.34 \\
-0.44 \\
0.36\end{array}$ \\
\hline $\begin{array}{l}\text { Age } \\
\text { Duration of illness } \\
\text { Levodopa dosage } \\
\text { NUDS } \\
\text { sBDI } \\
\text { AES }\end{array}$ & 0.26 & $\begin{array}{l}0 \cdot 14^{(b) I r} \\
0 \cdot 52^{*}\end{array}$ & $\begin{array}{c}- \text { mobile va } \\
0.40 \\
0.62^{*} \\
0.64 \dagger\end{array}$ & $\begin{array}{r}0.09 \\
0.15 \\
0.22 \\
-0.32\end{array}$ & $\begin{array}{c}0.13 \\
-0.38 \\
-0.09 \\
-0.34 \\
0.70 \dagger\end{array}$ & $\begin{array}{r}-0 \cdot 38 \\
-0 \cdot 23 \\
-0 \cdot 33 \\
-0 \cdot 34 \\
-0.37 \\
0.40\end{array}$ \\
\hline
\end{tabular}

* $p<0.05 ;$ tp $<0.01$. For abbreviations see text. 
Table 5 Controls. Spearman rank correlation coefficients for the main variables

\begin{tabular}{|c|c|c|c|c|c|}
\hline & $\begin{array}{l}\text { Duration of } \\
\text { illness }\end{array}$ & $N U D S$ & $s B D I$ & $A E S$ & $\begin{array}{l}\text { Mini-mental } \\
\text { state }\end{array}$ \\
\hline $\begin{array}{l}\text { Age } \\
\text { Duration of illness } \\
\text { NUDS } \\
\text { sBDI } \\
\text { AES }\end{array}$ & 0.56 & $\begin{array}{l}\text { (a) } M c \\
0.42 \\
0.69^{*}\end{array}$ & $\begin{array}{c}0.16 \\
0.70^{*} \\
-0.23\end{array}$ & $\begin{array}{c}-0.34 \\
-0.75^{*} \\
0.30 \\
-0.44\end{array}$ & $\begin{array}{r}-0.51 \\
-0 \cdot 10 \\
-0.24 \\
-0.36 \\
0.54\end{array}$ \\
\hline $\begin{array}{l}\text { Age } \\
\text { Duration of illness } \\
\text { NUDS } \\
\text { sBDI } \\
\text { AES }\end{array}$ & 0.56 & $\begin{array}{l}\text { (b) } I \mathrm{Imm} \\
0.38 \\
0.60^{*}\end{array}$ & $\begin{array}{c}\text { ile values } \\
0.24 \\
0.62^{*} \\
0.44\end{array}$ & $\begin{array}{c}-0.41 \\
-0.64^{*} \\
-0.28 \\
0.10\end{array}$ & $\begin{array}{r}-0.54 \\
-0.24 \\
-0.16 \\
-0.49 \\
0.56\end{array}$ \\
\hline
\end{tabular}

*p $<0.05$. For abbreviations see text.

Mean AES values and their changes in Parkinson's disease patients and controls are shown in fig 3. Mean mobile AES values do not significantly differ in the two groups. By contrast, during the immobile period there is a decrease in the AES score that appears to be much greater in Parkinson's disease patients than in controls $(p<0.001)$. The AES decrease during the immobile period is significant both within the Parkinson's disease and within the control group $(p<0.01$ and $<0.05$ respectively). dPD patients show a smaller decrease in their AES score during the immobile period than nPD patients $(p<0.01)$ (fig 4). This difference is absent in the control group (fig 4).

Mini-mental state In both groups values obtained during the mobile period do not differ significantly from the corresponding values in the immobile period.

Correlations (tables 4 and 5). During both the mobile and the immobile period, a significant $(p<0.05)$ correlation was found in the control, but not in the Parkinson's disease group, between sBDI/AES scores and duration of illness.

In Parkinson's disease patients, but not in controls, there was a significant $(p<0.05)$ correlation between NUDS and sBDI/AES scores in the mobile period. If the change in the measures during the immobile period is considered (immobile-mobile values), the increase in the NUDS scores does not correlate with that in the sBDI/AES scores among Parkinson's disease patients. There is a tendency to such a correlation among controls, but it does not attain statistical significance.

SBDI and AES scores in the mobile period and their changes in the immobile period show a strong $(p<0.01)$ correlation in the Parkinson's disease but not in the control group.

\section{Discussion}

Several methodological problems had to be solved in the course of our study of the affective changes attending end-of-dose deterioration in long-term levodopa treated Parkinson's disease patients. Careful selection of Parkinson's disease subjects was essential in order to exclude non-idiopathic cases: any conclusion drawn from studies including (for instance) atherosclerotic or toxic Parkinsonism cases would be misleading. The fluctuations in motor function had to have all the characters typical of end-ofdose deterioration, as described by Marsden and Parkes $^{17}$ for any proper assessment of affective behaviour during a period of central dopaminergic deficiency. We further had to exclude subjects presenting with signs of intellectual impairment, as detected by the Mini-mental state. ${ }^{16}$ Consequently, the number of Parkinson's disease patients acceptable for the study was fairly small. Selection of controls was equally strict. Reliable and simple instruments for assessing affective behaviour were required, since akinesia and other Parkinson's disease motor or sensory symtoms, exacerbated during end-of-dose deterioration, would distort several of the items belonging to the common scales used to rate depression. Although possible contamination of this kind could perhaps be tolerated in our experimental situation, where equally disabled groups were compared, we tried to keep it to a minimum by using the sBDI and the AES (see Method). The use of a control group consisting of subjects prone to intermittent physical disability (unrelated to CNS alterations) allowed us to discriminate the merely "reactive" depressive changes that might accompany "immobile" periods. Obviously, the increasing motor impairment and the general discomfort typical of end-of-dose deterioration can be expected to produce temporary adverse mood changes, as a result of a "psychological reaction". This important factor cannot be taken into account if normal subjects are selected as controls. Depression is common among subjects suffering from chronic rheumatic diseases, but is thought to be a "psychological 
reaction" to pain and gradually declining function. ${ }^{29}$ This being so, we expected a comparative study of affective behaviour in Parkinson's disease and rheumatoid arthritis patients to highlight the "neurobiological" substrates of Parkinson's disease depression. Although the two groups were evaluated on the Mini-mental state ${ }^{16}$ both in the mobile and the immobile period (without finding any significant difference), we did not make a comprehensive assessment of their intellectual function. In our preliminary study, ${ }^{2}$ concomitant evaluation of mood and cognitive performance proved to be difficult: patients unduly burdened with questions and tests seemed to be less cooperative and reliable. Besides, Brown et al ${ }^{11}$ stressed that adverse changes in mood and alertness tended to trigger the functional cognitive impairment which characterised a proportion of their "off" Parkinson's disease patients. Thus, we thought it was justified to study mood and activation changes in their own right; moreover, it seemed unlikely that subtle and inconstant cognitive changes could affect the simple self-rating scales we used.

Our results showed that the overall physical disability was similar in the Parkinson's disease and the control group, both in the mobile and the immobile period. Thus, the most important condition for a correct comparison was fulfilled. Thus, as far as group results are concerned, two main points arise:

(1) In the mobile period signs and symptoms of depression were present both among Parkinson's disease patients and controls. However, they were significantly more common in the former group, a finding that confirms those of Robins. ${ }^{4}$ Assuming that the adverse mood changes in the control group were an example of steady "psychological reaction" to chronic disability, the higher incidence of depression in the Parkinson's disease group may indicate further depressive mechanisms, perhaps related to the pathobiology of Parkinson's disease. This is indirectly supported by the different clinical features of depression in the two groups, as evaluated on the DSM III criteria. $^{27}$

(2) During the immobile period, that is during the temporary increase in disability, a worsening of mood and, even more, of self-rated psychic activation was found both in the Parkinson's disease and in the control groups. However, it was significantly greater among Parkinson's disease patients. It must be remembered that adverse changes in the "affect/arousal state" were described by Brown et al ${ }^{11}$ as an important feature of the "off" period of their long-term levodopa treated Parkinson's disease subjects. The present study reliably confirms this finding thanks to the use of a control group as disabled as the Parkinson's disease group. If the depressive changes temporarily observed among controls in the immobile period were likely to be a transient "psychological reaction" to increased motor impairment, the significantly more severe mood alterations found in the Parkinson's disease group further support the view that they were not only secondary to physical disability, but had a neurobiological substrate. Since the CNS change known to occur during end-of-dose deterioration (that is, the immobile period of Parkinson's disease patients) is hypofunction of dopamine systems, there might be a link between central dopaminergic deficiency and intermittent disturbances of mood and activation in our Parkinson's disease patients. However, although primary or secondary changes in non-dopaminergic neurotransmitter systems during end-of-dose deterioration are not known, they cannot be ruled out a priori. Many of such systems are involved in the pathobiology of Parkinson's disease (norepinephrinergic, serotonergic, GABAergic and peptidergic neurons). ${ }^{930}$ Since a role of these structures in modulating affective behaviour is often hypothesised or even proved, ${ }^{31}$ this aspect of the problem must not be overlooked.

If individual results are considered, it is evident that the reversible increase in disability typical of the immobile period was associated with a less severe worsening of mood and psychic activation in "steadily depressed" than in "non-steadily depressed" Parkinson's disease subjects, a finding that was not seen among controls. There are two possible explanations for this phenomenon: (a) "steady depression" in our Parkinson's disease subjects was related to biological mechanisms largely independent of dopaminergic involvement; (b) in our "steadily depressed" Parkinson's disease patients there was a permanent, structural derangement of dopamine pathways modulating some aspects of affective behaviour so severe as to prevent any important functional fluctuation. If this is true, the dissociation between motor swings and mood features would imply that the latter were related to non-nigrostriatal dopamine function. Only interpretation (b) is consistent with all our results.

In the Parkinson's disease patients, in contrast to the controls, severity of depression did not correlate with duration of illness, a finding which would indirectly support the "primary" genesis of their depressive symptoms. On the other hand, a correlation was found in the Parkinson's disease, but not in the control group, between depression and disability during the mobile period. This finding might be an argument in favour of a "reactive" genesis of mood alterations in our Parkinson's disease patients. However, we were previously able to show that the presence of depression may be a cause, rather than an effect, of increased disability in a Parkinson's disease population. ${ }^{2}$ In any case, no correlation was found in the Parkinson's disease group between the change in dis- 
ability and the change in the depressive scores during immobility, whereas such a trend was revealed in the controls, although it was not statistically significant.

In no case did we observe very dramatic, cyclical swings in mood of Parkinson's disease patients resembling those of the hypomanic-depressive illness and paralleling the "on" and the "off" periods. In every instance adverse mood changes in the Parkinson's disease group were accompanied by a significant worsening of self-rated psychic activation, as evaluated by the AES. In those subjects in whom mood did not change, psychic activation did not change. Classically, levodopa is thought to exert a general "arousing" influence on Parkinson's disease subjects, so that lower levels of alertness, at least as subjectively appreciated, seem to be an obvious finding during end-ofdose deterioration, a condition associated with low or falling plasma levodopa levels. ${ }^{17-19}$ Besides, the close parallelism of mood and activation features in our Parkinson's disease patients led us to speculate that these two altered aspects of psychic function may have some common anatomophysiological impairment, related to CNS dopaminergic mechanisms.

Altered dopamine metabolism has been reported in subgroups of patients affected by retarded depression, even without Parkinson's disease. ${ }^{32}$ The effect of tricylic antidepressants, which can relieve Parkinson's disease depression, ${ }^{3}$ may be mediated by interaction with dopaminergic neurotransmission. ${ }^{33}$ Moreover, Mayeux et al $^{34}$ found homovanillic acid levels lower in the CSF of Parkinson's disease patients with a "major depression" than in the others. Although these authors did not comment on this feature of their results, it might suggest that a severe, widespread derangement of dopamine metabolism, resulting from the combined failure of nigro- and non-nigrostriatal dopamine systems, may underlie or predispose to major depression in Parkinson's disease. However, this interpretation was later challenged by the authors themselves, who stressed the importance of abnormal serotonin metabolism in depressed Parkinsonians. ${ }^{7}$

In our opinion, the interactions between the neurotransmitter and neuromodulator systems damaged in Parkinson's disease are too complex for depression to be ascribed to one or other of the neural structures. In any case, our study does not provide conclusive evidence to exclude the "reactive" process as a causal factor of Parkinson's disease depression. However, the higher overall level of depression in the Parkinson's disease group, their more adverse mood changes accompanying increased disability and the peculiarities of affective behaviour within the group itself showed that a "reactive" model is not sufficient to explain their depression. We are inclined to think that biological mechanisms were also at work, and that central dopaminergic deficiency probably played a predisposing or contributory role.
Preliminary results of this study were presented at the First Meeting of the Italian Society of Neurosciences (Rome, 12-15 Dec, 1984).

Work supported in part by Regione Piemonte, grant No 17.

We thank Dr Masahiro Nomoto for his helpful criticism, Dr JPR Dick for editorial comment and Prof CD Marsden for having read the paper.

\section{Appendix}

ACTIVATION AND EUPHORIA SCALE

Self-rating scale items (0-6 points).

1. Feel active

2. Feel alert

3. Feel excited

4. Feel talkative

5. Feel close to people

6. Feel confident.

\section{References}

${ }^{1}$ Mayeux R, Stern Y, Rosen J, Leventhal J. Depression, intellectual impairment and Parkinson's disease. Neurology 1981;31:645-50.

${ }^{2}$ Cantello R, Riccio A, Scarzella L, et al. Depression in Parkinson's disease: a disabling but neglected factor. Ital J Neurol Sci 1984;5:417-22.

${ }^{3}$ Mayeux R, Williams JBW, Stern J, Cote L. Depression and Parkinson's disease. In: Hassler RG, Christ JF, eds. Parkinson-specific Motor and Mental Disorders. Role of the Pallidum: Pathophysiological, Biochemical and Therapeutic Aspects. Advances in Neurology, vol 40. New York: Raven Press, 1984:241-50.

${ }^{4}$ Robins AH. Depression in patients with parkinsonism. $\mathrm{Br}$ J Psychiatry 1976;128:141-5.

${ }^{5}$ Agid Y, Ruberg M, Dubois B, Javoy-Agid F. Biochemical substrates of mental disturbances in Parkinson's disease. In: Hassler RG, Christ JF, eds. Parkinson-specific Motor and Mental Disorders. Role of the Pallidum: Pathophysiological, Biochemical and Therapeutic Aspects. Advances in Neurology, vol 40. New York: Raven Press, 1984:211-8.

${ }^{6}$ Fibiger HC. The neurobiological substrates of depression in Parkinson's disease: a hypothesis. Can J Neurol Sci 1984;11:105-7.

${ }^{7}$ Mayeux R, Stern Y, Cote L, Williams JBW. Altered serotonin metabolism in depressed patients with Parkinson's disease. Neurology 1984;34:642-6.

${ }^{8}$ Javoy-Agid F, Agid Y. Is the mesocortical dopaminergic system involved in Parkinson's disease? Neurology 1980;30:1326-30.

${ }^{9}$ Javoy-Agid F, Ruberg M, Taquet H, et al. Biochemical neuropathology of Parkinson's disease. In: Hassler RG, Christ JF, eds. Parkinson-specific Motor and Mental Disorders. Role of the Pallidum: Pathophysiological, Biochemical and Therapeutic Aspects. Advances in Neurology, vol 40. New York: Raven Press, 1984:189-98. 
Biochemical and Therapeutic Aspects. Advances in Neurology, vol 40. New York: Raven Press, 1984:189-98.

${ }^{10}$ Klein D. Endogenomorphic depression: a conceptual and terminological revision. Arch Gen Psychiatry 1974;31: 447-54.

${ }^{11}$ Brown RG, Marsden CD, Quinn N, Wyke MA. Alterations in cognitive performance and affect-arousal state during fluctuations in motor function in Parkinson's disease. J Neurol Neurosurg Psychiatry 1984;47:454-65.

12 Nutt JG, Carter JH. Sensory symptoms in Parkinsonism related to central dopaminergic function. Lancet 1984; ii:456-7.

${ }^{13}$ Delis D, Direnfeld L, Alexander MP, Kaplan E. Cognitive fluctuations associated with on-off phenomenon in Parkinson's disease. Neurology 1982;32:1049-52.

${ }^{14}$ Hardie RJ, Lees AJ, Stern GM. On-off fluctuations in Parkinson's disease. A clinical and neuropharmacological study. Brain 1984;107:487-506.

${ }^{15}$ Hachinski VC, Linnette D, Zilhka E, et al. Cerebral blood flow in dementia. Arch Neurol 1975;32:632-7.

${ }^{16}$ Folstein M, Folstein S, McHugh PJ. "Mini-mental State": a practical method for grading the cognitive state of patients for the clinician. $J$ Psychiatric Res 1975;12:189-98.

${ }^{17}$ Marsden CD, Parkes JD. "On-off” effects in patients with Parkinson's disease on chronic levodopa therapy. Lancet 1976;i:292-6.

${ }^{18}$ Tolosa ES, Martin WE, Cohen HP, et al. Patterns of clinical response and plasma levodopa levels in Parkinson's disease. Neurology 1975;25:177-83.

${ }^{19}$ Shoulson I, Glaubiger GA, Chase TN. On-off response. Clinical and biochemical correlations during oral and intravenous levodopa administration in parkinsonian patients. Neurology 1975;25:1144-8.

${ }^{20}$ Gilliland BC, Mannik M. Rheumatoid Arthritis: In: Thorn GW, Adams RD, Braunwald E, Isselbacher KJ, Petersdorf RG, eds. Harrison's Principles of Internal Medicine. 8th Edition. Tokyo: McGraw-Hill Kogakusha, 1977:2050-9.

${ }^{21}$ Canter GJ, de la Torre R, Mier MA. A method for evaluating disability in patients with Parkinson's disease. $J$ Nerv Ment Dis 1961;133:143-7.
${ }^{22}$ Beck AT, Ward CH, Mendelson M, et al. An inventory for measuring depression. Arch Gen Psychiatry 1961; 4:53-63.

${ }^{23}$ Stern J, Mayeux R, Rosen J. Contribution of perceptual motor dysfunction to construction and tracing disturbances in Parkinson's disease. J Neurol Neurosurg Psychiatry 1984;47:983-9.

${ }^{24}$ Direnfeld LK, Albert ML, Volicer L, et al. Parkinson's disease. The possible relationship of laterality to dementia and neurochemical findings. Arch Neurol 1984;41:935-41.

${ }^{25}$ Van Kammen DP, Murphy DL. Attenuation of the euphoriant and activating effects of d- and 1- Amphetamine by lithium carbonate treatment. Psychopharmacologia 1975;44:215-24.

${ }^{26}$ Yokel RA, Wise RA. Attenuation of intravenous amphetamine reinforcement by central dopamine blockade in rats. Psychopharmacology 1976;48:311-8.

${ }^{27}$ American Psychiatric Association. Diagnostic and Statistical Manual of Mental Disorders. 3rd ed. Washington DC, 1980:205-24.

${ }^{28}$ Schwab J, Bialow M, Clemmons R, et al. The Beck Depression Inventory with medical inpatients. Acta Psychiatry Scand 1967;43:255-66.

${ }^{29}$ Zaphiropoulos G, Burry HC. Depression in rheumatoid disease. Ann Rheum Dis 1974;33:132-5.

${ }^{30}$ Marsden CD. Basal Ganglia Disease. Lancet 1982;ii: 1141-6.

${ }^{31}$ van Praag HM. Depression. Lancet 1982;ii:1259-64.

${ }^{32}$ van Praag HM, Korf J. Retarded depression and the dopamine metabolism. Psychopharmacology 1971;19: 199-203.

${ }^{33}$ Serra G, Argiolas A, Klimek V, et al. Chronic treatment with antidepressants prevents the inhibitory effect of small doses of apomorphine on dopamine synthesis and motor activity. Life Sci 1979;25:415-24.

${ }^{34}$ Mayeux R, Cote L, Stern Y, Williams JBW. Depression in Parkinson's disease: alterations in monoamine metabolism. Neurology 1983;33(Suppl 2)Abstract 103.

${ }^{35}$ Hoehn MM, Yahr MD. Parkinsonism: onset, progression and mortality. Neurology 1967;17:427-42. 